\title{
Resenha de M. Azucena Penas Ibáñez (ed.): La traducción. Nuevos planteamientos teórico- metodológicos (síntesis, colección síntesis inves- tigación, 2015. 372 páginas)
}

\author{
Daniel Gallego Hernández*
}

Cuando se me ofreció la posibilidad de reseñar el libro La traducción. Nuevos planteamientos teórico-metodológicos no dudé ni un momento en aceptar el encargo, pues el título que lleva la obra me hizo pensar en la necesidad que tenemos no solo los formadores e investigadores, sino también los estudiantes e incluso los profesionales, de actualizar los conocimientos sobre una actividad tan compleja como es la traducción.

Se trata de un libro editado por M.․ Azucena Penas Ibáñez, profesora titular en el Departamento de Filología española de la Universidad Autónoma de Madrid. Al consultar sus trabajos registrados en la base de datos de Dialnet no solo me quedé asombrado por el extenso currículum de la editora, sino también por su reciente interés por la traductología (de hecho, la propia editora lo reconocer en la presentación de la obra). A mi modo de ver, esto último es un hecho digno de reseñar, pues da cuenta de la elevada capacidad que tiene esta investigadora para afrontar nuevos retos y explorar nuevos campos distintos a los que llevaba investigando desde principios de los años noventa (la lingüística española).

Los indicios de calidad de la obra también quedan patentes tanto por su contenedor como por su contenido. Por una parte, el libro está publicado en una editorial que, a día de hoy, figura dentro de las diez mejores de España en la rama de Lingüística, Literatura y Filología según el sistema de

\footnotetext{
* Doutor em Tradução e Interpretação e atualmente ensina tradução especializada em economia e terminologia no Departamento de Traducción e Interpretación da Universidad de Alicante.
} 
información SPI (Scholarly Publishers Indicators). Asimismo, el índice de contribuidores es otro buen indicador, no solo por el bajo nivel de endogamia (de los veintidós académicos que participan en el libro, seis son docentes en la misma universidad a la que pertenece la editora, lo que supone una tasa por debajo del treinta por ciento), sino también por sus categorías profesionales (a los cinco catedráticos que participan en la obra, se les suman trece profesores titulares, además de, entre otros, profesionales de la traducción). A ello cabe añadir la capacidad de liderazgo y coordinación de M. aㅡ Azucena Penas Ibáñez, por haber conseguido hacer coincidir a formadores e investigadores de universidades de distintos puntos geográficos (Barcelona, Córdoba, León, Madrid, Murcia, Oslo, Oxford, País Vasco, Salamanca, Valencia, Varsovia, Zaragoza).

Por otra parte, la calidad del libro viene también dada por su contenido, que abarca distintos campos de la traducción al tiempo que propone una renovada metodología, así como diversos análisis teóricos de la traducción, relacionados con seis aspectos concretos que, a su vez, son las seis partes en las que se estructura la obra: la lingüística, las tipologías textuales, la poética, el género, la sociología y la semiótica.

La primera parte, Lingüística y traducción, se divide, a su vez, en cuatro capítulos: "Semántica de la traducción automática", a cargo de Ramón Cerdà Massó (Universidad de Barcelona); “Traducción y lingüística cognitiva" redactado por Javier Valenzuela (Universidad de Murcia) y Ana M. a Rojo (Universidad de Murcia); “La traducción intralingüística”, cuya autora es la propia M. a Azucena Penas (Universidad Autónoma de Madrid); y “Traducción, interacción y retroacción: una relectura de Benjamin y de Man desde la teoría materialista del discurso", de José Ángel García Landa (Universidad de Zaragoza). El denominador común de estos capítulos es la lingüística, entendida de manera amplia, en su relación con la traducción. En ellos, el lector podrá introducirse en distintos campos, como el de la traducción automática, a través de las diferentes etapas que esta ha vivido y el desarrollo del que se ha beneficiado; el de la lingüística cognitiva y su repercusión en la traductología (estudio del proceso traductor frente a estudios del producto de traducción) con especial énfasis en los estudios de corte contras- 
tivo, o el de la traducción intralingüística, muy poco investigada en los estudios de traducción, y de la que se ofrece una profundización de las relaciones que establece con la sinonimia sintagmática. También en esta primera parte encontramos una nueva exposición de las ideas expuestas en The task of the translator, de Walter Benjamin.

La segunda parte, titulada Tipología textual y traducción, consta de tres capítulos: “Traducción de textos jurídicos y administrativos", de Esther Vázquez y del Árbol (Universidad Autónoma de Madrid); “La traducción de textos económicos: principales características y dificultades", de Verónica Román Mínguez (Universidad Autónoma de Madrid); y “La traducción de textos humorísticos multimodales", de Javier Muñoz-Basols (Universidad de Oxford) y Micaela Muñoz-Calvo (Universidad de Zaragoza). Esta parte entra de lleno una de las actuales vías de investigación de los estudios de traducción: los géneros textuales. En concreto, el lector puede encontrar diferentes clasificaciones o taxonomías textuales relativas a los ámbitos jurídico-administrativo y económico-financiero, además de repasar algunos géneros humorísticos multimodales. A ello se suma el estudio las características textuales que presentan tales ámbitos, las dificultades que presenta su traducción en la combinación de idiomas inglés-español o la descripción de algunas técnicas empleadas para traducir el humor.

La tercera parte se llama Poética y traducción y está compuesta de otros tres capítulos: "Traducción del cuarto género (el ensayo)", de Javier Ortiz García (Universidad Autónoma de Madrid); “'Teoría de la traducción poética (inglés-español): traductores, traducciones y antologías. Práctica: algunos ejemplos relevantes", de Ángeles García Calderón (Universidad de Córdoba); y "Traducción del género dramático", redactado por Rosa I. Martínez Lillo (Universidad Autónoma de Madrid). Si bien esta parte podría considerarse continuación de la anterior, en la medida en que se continúan estudiando distintos géneros textuales, lo cierto es que esta se distingue de la segunda al centrarse, en esencia, en el ámbito de la traducción literaria. En este sentido, el lector encontrará una aproximación al análisis de las características del ensayo como texto literario, y a algunos aspectos de su traducción, como las notas a pie de página, las citas o los índices, además del eterno di- 
lema entre la domesticación y la extranjerización. Asimismo, esta parte también está dedicada a la traducción poética y teatral, cuyos respectivos capítulos ofrecen al lector, entre otras cosas, un breve recorrido por la traducción de la poesía inglesa y el teatro árabe.

La cuarta parte, Género y traducción, tiene dos capítulos: “Traducción y género: evolución teórica y práctica de una poética feminista", de Eulalia Piñero Gil (Universidad Autónoma de Madrid), y "Traducción y globalización de estereotipos de género en televisión: una imagen panorámica", de María Pérez López de Heredia (Universidad del País Vasco). En esta parte, el lector conocerá no solo cómo desde el pasado siglo XX el feminismo lleva luchando por que, a través de la traducción, se evite el sexismo en la literatura, sino también, en el ámbito de los medios audiovisuales, la conveniencia de reconsiderar el concepto de género en aras de una "interseccionalidad" que neutralice cuestiones tanto de sexo como de religión e incluso raza.

La penúltima parte se titula Sociología y traducción y consta de otros dos capítulos. Por una parte, encontramos el capítulo “La traducción de tratados bilaterales entre España y Marruecos: el caso de la asistencia judicial en materia penal". Sus autores, Arlette Véglia (Universidad Autónoma de Madrid) y Eric Stachurski (Universidad de Varsovia), coinciden en que el traductor para el campo de la cooperación judicial penal entre España y los países del África francófona no puede limitarse a traducir, sino que debe convertirse, además de jurista, en un verdadero "diplomático lingüista". Por otra parte, Carlos Fortea (Universidad de Salamanca) escribe el capítulo “Un destino alemán y un destino español. La traducción de literatura alemana en la España del siglo XX". En él traza un recorrido cronológico con el ánimo de mostrar que la traducción al español de la literatura alemana del siglo pasado se ha visto mermada no tanto por motivos relacionados con el tópico de la densidad o la complejidad, sino por factores económicos y políticos.

Cierra la obra la parte titulada Semiótica y traducción, compuesta de tres capítulos. En el primero de ellos, “La traducción y su rol hibridizador en la semiosfera: Fenollosa, Hearn, Pound y Noguchi", Beatriz Penas Ibáñez (Universidad de Zaragoza) muestra la necesidad de reconceptualizar la traducción per se como proceso posibilitador de la comprensión de lo diverso y 
como proceso de gestión discursiva tendente a la convergencia interpretativa, además de señalar la importancia del traductor individual dentro del proceso de gestión discursiva, a través de traductores de formas poéticas japonesas, como hakais y haikus. Le sigue el capítulo “La traducción de la literatura infantil y juvenil: ideología y polisistema de recepción", a cargo de Beatriz Soto Aranda (Universidad Rey Juan Carlos), quien analiza las características de la traducción de este tipo de literatura prestando especial atención a las normas que condicionan el proceso de traducción e inserción de una obra dentro del polisistema meta, pues estas, al inscribirse en el marco de la ideología, van más allá de ser meros procedimientos aplicables de forma regular a las traducciones. En el último capítulo, "Traducción cinematográfica y traducción intersemiótica: la traducción audiovisual", Jeroen Vandaele (Universidad de Oslo) comenta una serie de aspectos relacionados con diferentes modalidades de traducción (doblaje, voice-over, subtitulado, subtítulos para discapacitados auditivos, sobretitulación, respeaking y audiodescripción) y concluye que la traducción audiovisual amplía el alcance de los textos audiovisuales originales, pues les permite romper fronteras no solo lingüísticas y semióticas, sino también aquellas levantadas por discapacidades.

Estas seis partes de la obra están precedidas por un prólogo de Salvador Gutiérrez Ordóñez (Universidad de León) y un epílogo a cargo de Ángel López García-Molins (Universidad de Valencia).

Por otro lado, llama la atención la disposición de las referencias bibliográficas citadas a lo largo de cada capítulo, cuyo listado completo debe consultarse en el sitio web de la propia editorial (http://www.sintesis.com/data/uploads/files/Biblioweb\%20\%20-

\%20La\%20traduccion.pdf), pues al final del libro impreso el lector solo encontrará un breve listado de referencias de cada capítulo.

En resumidas cuentas, nos encontramos ante una obra de consulta que perfectamente puede tener cabida dentro de los planes de estudio de traducción e interpretación, ya sea a nivel del grado, ya sea a nivel de máster, ya sea a nivel de doctorado. En este sentido, el traductor en formación podrá conocer algunos de los aspectos más interesantes relacionados con uno $\mathrm{u}$ 
GALLEGO HERNÁNDEZ Resenha de M. ${ }^{a}$ Azucena Penas Ibáñez (ed.): La traducción. Nuevos planteamientos teórico-metodológicos

otro tipo de traducción a los que deberá enfrentarse a lo largo de su formación. Asimismo, el joven traductólogo encontrará en la obra algún tema o aproximación metodológica que podrá tener en cuenta en su periplo investigador.

Resenha do livro La traducción. Nuevos planteamientos teórico-metodológicos, organizado por M.․ Azucena Penas Ibáñez, Professora Titular do Departamento de Filología española da Universidad Autónoma de Madrid.

Reseña del libro La traducción. Nuevos planteamientos teórico-metodológicos, editado por M. a Azucena Penas Ibáñez, profesora titular en el Departamento de Filología española de la Universidad Autónoma de Madrid. 